\title{
ADUBAÇÃO FOSFATADA NO MELOEIRO-AMARELO: REFLEXOS NA PRODUÇÃO E QUALIDADE DOS FRUTOS ${ }^{1}$
}

\author{
FRANCISCO LUIS GONÇALVES DE ABRÊㄴㄹ, JAIRO OSVALDO CAZETTA³, \\ TEREZINHA FERREIRA XAVIER ${ }^{4}$
}

RESUMO - O melão (Cucumis melo L.) é uma das culturas de grande expressão econômica e social para a região Nordeste do Brasil. Apesar disso e dos baixos níveis de fósforo (P) dos solos tropicais, existem poucas pesquisas sobre adubação com $P$ nesta cultura, embora seja frequentemente mencionado que este nutriente tem papel preponderante na produção e qualidade dos frutos. Neste contexto, objetivou-se com este trabalho avaliar o efeito de doses de $\mathrm{P}\left(0 ; 120 ; 240 ; 360\right.$ e $480 \mathrm{~kg} \mathrm{ha}^{-1}$ de $\left.\mathrm{P}_{2} \mathrm{O}_{5}\right)$, na produção e qualidade do melão-amarelo híbrido Goldex $\mathrm{F}_{1}$, nas condições ambientais de Teresina - Piauí. $\mathrm{O}$ experimento foi conduzido em um delineamento de blocos ao acaso, com quatro repetições, tendo 40 plantas por parcela. Os frutos foram colhidos aos 75 após o plantio. Foram avaliados os dados médios da produção total, produção de frutos comerciais, massa e número de frutos por planta, comprimento e diâmetro de frutos, espessura da polpa de frutos, sólidos solúveis, acidez titulável e o índice de maturação. A produção total e comercial, assim como a massa e o número de frutos e acidez titulável aumentaram com as doses de $\mathrm{P}$ aplicadas até a dose de $278 \mathrm{~kg} \mathrm{ha}^{-1}$ de $\mathrm{P}_{2} \mathrm{O}_{5}$. Doses acima de $278 \mathrm{~kg} \mathrm{ha}^{-1}$ de $\mathrm{P}_{2} \mathrm{O}_{5}$ prejudicaram a produtividade de frutos classificados como comerciais. O comprimento, o diâmetro de frutos e a espessura de polpa aumentaram até a dose de $355 \mathrm{~kg} \mathrm{ha}^{-1}$ de $\mathrm{P}_{2} \mathrm{O}_{5}$, com aumentos pouco expressivos entre 278 e $355 \mathrm{~kg} \mathrm{ha}^{-1}$ de $\mathrm{P}_{2} \mathrm{O}_{5}$. $\mathrm{O}$ teor de sólidos solúveis totais não foi afetado pela adubação fosfatada. Para as condições de fertilidade do solo deste trabalho, recomenda-se uma dose ao redor de $275 \mathrm{~kg} \mathrm{ha}^{-1}$ de $\mathrm{P}_{2} \mathrm{O}_{5}$.

Termos para indexação: Cucumis melo; Fósforo; sólidos solúveis; acidez, índice de maturação.

\section{PHOSPHORUS FERTILIZATION ON MELON: REFLEXES ON FRUITS PRODUCTION AND QUALITY}

\begin{abstract}
The culture of melon (Cucumis melo L.) has a great economic and social expression for the Northeast region of Brazil. Although its importance in the Brazilian agriculture, and the low levels of phosphorus $(\mathrm{P})$ on tropical soils, there are reduced number of researches regarding $\mathrm{P}$ fertilization for this culture, even though is frequently mentioned that this nutrient would have preponderant rules on the development, growth and quality of the fruits. Thus, the objective of this study was to evaluate the effect of $\mathrm{P}$ doses on the production and quality of yellow cantaloupes, hybrid Goldex F1, growing under Teresina-PI conditions. The experiment was composed by $5 \mathrm{P}$ doses $\left(0,120,240,360\right.$ and $480 \mathrm{~kg} \mathrm{ha}^{-1}$ of $\left.\mathrm{P}_{2} \mathrm{O}_{5}\right)$, carried out in four randomized blocks design. The fruits were harvested at 75 days after planting, and evaluated the total production; production of commercial fruits; mass and number of fruits per plant; length and diameter of fruits; pulp thickness, soluble solids, acidity and maturation index. The results indicated that the total and commercial production, mass and number of fruits as well as acidity increased with $\mathrm{P}$ doses, reaching the maximum values at $278 \mathrm{~kg} \mathrm{ha}^{-1} \mathrm{P}_{2} \mathrm{O}_{5}$. Doses above $278 \mathrm{~kg} \mathrm{ha}^{-1} \mathrm{P}_{2} \mathrm{O}_{5}$ harmed the productivity. The fruits

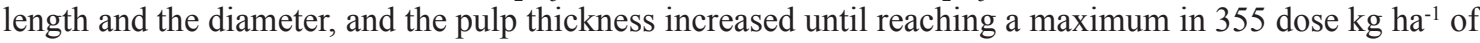
$\mathrm{P}_{2} \mathrm{O}_{5}$, although with little improvement from 278 to $355 \mathrm{~kg} \mathrm{ha}^{-1}$ of $\mathrm{P}_{2} \mathrm{O}_{5}$. The level of total soluble solids was not affected by $\mathrm{P}$ fertilization. Under similar conditions to this research, it is recommended a dose around $275 \mathrm{~kg} \mathrm{ha}^{-1}$ de $\mathrm{P}_{2} \mathrm{O}_{5}$.
\end{abstract}

Index terms: Cucumis melo, Phosphorus, soluble solids, acidity, maturation index.

\footnotetext{
1'(Trabalho 224-10). Recebido em: 25-10-2010. Aceito para publicação em: 05-10-2011.

${ }^{2}$ Eng. Agron., MS., Doutorando em Agronomia (Produção Vegetal) pelo convênio DINTER entre a UNESP/Jaboticabal-SP e a UFPI/ Teresina-PI. E-mail: fluisga@yahoo.com.br

${ }^{3}$ Eng. Agron, Dr., Professor Adjunto do Departamento de Tecnologia da FCAV/UNESP, Jaboticabal. Via de acesso Prof. Paulo Donato Castellane, s/n, 14.884-900, Jaboticabal-SP. E-mail: cazetta@fcav.unesp.br

${ }^{4}$ Eng. Agron., MS., Doutoranda em Agronomia (Ciência do Solo), FCAV/UNESP, Jaboticabal-SP. E-mail: teferxa@hotmail.com
} 


\section{INTRODUÇÃO}

O melão (Cucumis melo L.) é uma das culturas de maior expressão econômica e social para a região Nordeste do Brasil. Esta cultura intensificouse no Nordeste nas duas últimas décadas, pela introdução de avançadas técnicas de cultivo (fertirrigação, cultivo em alta densidade, cultivo em ambiente protegido) que potencializaram as condições naturais da região (temperaturas elevadas e luminosidade durante praticamente todo o ano) para produção de melão (VIANA et al., 2007). No ano de 2007, o melão alcançou o maior volume exportado de fruta in natu$r a$, com 204,5 mil toneladas, tendo como principais destinos os países do continente Europeu, gerando divisas de 128,21 milhões de dólares (AGRIANUAL, 2009).

A intensificação dos cultivos de melão requer maior eficiência na aplicação de fertilizantes, principalmente dos fosfatados, uma vez que o fósforo é o nutriente aplicado em maior quantidade, de acordo com as recomendações de adubação no Brasil. Este fato ocorre devido à baixa disponibilidade de fósforo nos solos tropicais associada à sua baixa mobilidade no solo e alta afinidade por óxidos de ferro e alumínio (NOVAIS et al., 2007), bem como à baixa eficiência de aquisição e de utilização do fósforo pelas plantas (WANG et al., 2010), o que aumenta a necessidade de sua incorporação em programas de adubação.

Apesar da importância da cultura meloeira para a agricultura brasileira, existem poucas pesquisas sobre o fósforo nesta cultura, embora seja mencionado de forma geral que este nutriente tem papel preponderante no desenvolvimento, floração e frutificação das plantas, e particularmente do melão, agindo como fator decisivo para a qualidade dos frutos (FARIA et al., 1994; BRITO et al., 2000). Sua eficiência é atribuída ao aumento do número de frutos e, de acordo com Brito et al. (2000), o fósforo também influencia o teor de sólidos solúveis dos frutos. Entretanto, em um levantamento realizado na Revista Brasileira de Fruticultura nos últimos dez anos, apenas um trabalho (SILVA et al., 2010) foi publicado relacionando fósforo com produção e qualidade de melão, e revisão recente sobre eficiência de aquisição e utilização de fósforo pelas culturas modernas (WANG et al., 2010) nem cita o melão, evidenciando a carência de informações. Neste sentido, objetivouse com este trabalho avaliar o efeito de cinco doses de fósforo $\left(0 ; 120 ; 240 ; 360\right.$ e $\left.480 \mathrm{~kg} \mathrm{ha}^{-1} \mathrm{de}_{2} \mathrm{O}_{5}\right)$ na produtividade e qualidade física e química do melão-amarelo, híbrido Goldex $\mathrm{F}_{1}$, nas condições ambientais do município de Teresina, Piauí.

\section{MATERIAL E MÉTODOS}

$\mathrm{O}$ experimento foi conduzido entre maio e agosto de 2008, na área experimental da Universidade Federal do Piauí, em Teresina-PI, localizada a $05^{\circ} 05^{\prime}$ de latitude $\mathrm{S}, 42^{\circ} 48^{\prime}$ de longitude $\mathrm{W}$, e a $110 \mathrm{~m}$ de altitude, com clima tropical, com chuvas de verão e outono, precipitação média anual de $1.377 \mathrm{~mm}$, evapotranspiração potencial média anual de 2.973 mm, umidade relativa do ar média anual de $69,9 \%$, insolação total anual de 2.625 horas, e temperatura média anual de $28^{\circ} \mathrm{C}$ (MEDEIROS, 2006).

O solo utilizado no experimento foi classificado como Argissolo Vermelho-Amarelo (SANTOS, 2006), com a seguinte composição física da camada de 0 a $20 \mathrm{~cm}$ : Argila $=40 \mathrm{~g} \mathrm{~kg}^{-1}$; silte $=100 \mathrm{~g} \mathrm{~kg}^{-1}$ e areia $=860 \mathrm{~g} \mathrm{~kg}^{-1}$. Os principais atributos relacionados à fertilidade do solo, determinados conforme Raij et al. (2001), estão apresentados na Tabela 1.

$\mathrm{Na}$ adubação de plantio, foram aplicados no sulco aberto com profundidade de $15 \mathrm{~cm}: 30 \mathrm{~kg} \mathrm{ha}^{-1}$ $\mathrm{N}$ (sulfato de amônio), $80 \mathrm{~kg} \mathrm{ha}^{-1}$ de $\mathrm{K}_{2} \mathrm{O}$ (cloreto de potássio) e, em forma de pulverização no sulco aberto na linha de plantio, também foram aplicados $1 \mathrm{~kg} \mathrm{ha}^{-1}$ de B (Bórax) e $3 \mathrm{~kg} \mathrm{ha}^{-1}$ de Zn (sulfato de zinco). O P foi aplicado na fundação conforme as doses estabelecidas nos tratamentos, na forma de superfosfato triplo. Seguindo as indicações descritas em Granjeiro et al. (2002), em cobertura, foram aplicados $100 \mathrm{~kg} \mathrm{ha}^{-1}$ de $\mathrm{N}$ (ureia) e $100 \mathrm{~kg} \mathrm{ha}^{-1}$ de $\mathrm{K}_{2} \mathrm{O}$ (cloreto de potássio), parcelados em três vezes, sendo $20 \%, 30 \%$ e $50 \%$, aos $15 ; 30$ e 50 dias após o transplantio das mudas, respectivamente, aplicados lateralmente e ao longo da linha de plantio.

O genótipo de melão-amarelo utilizado foi o Goldex $F_{1}$. Para a obtenção das mudas, as sementes foram semeadas em bandejas de poliestireno expandido (128 células) contendo substrato para plantas, sendo uma semente por célula. $O$ transplantio no campo foi realizado onze dias após a semeadura. Para isso, foram escolhidas as mudas mais uniformes, as quais foram transportadas para a área experimental e plantada uma planta por cova, no espaçamento de $0,25 \mathrm{~m}$ entre plantas e $2 \mathrm{~m}$ entre as linhas.

As datas de semeadura, transplante no campo e colheita, bem como as condições de temperatura e precipitação pluvial estão apresentadas na Figura 1. Pode-se observar, nos dados da Figura 1, que ocorreram chuvas significativas até o mês de maio, mas após o transplante no campo choveu apenas cerca de $5 \mathrm{~mm}$, e a temperatura média do ar variou em torno de $26{ }^{\circ} \mathrm{C}$. Essas condições climáticas desse período foram bastante semelhantes às médias históricas da região para temperatura e precipitação pluvial, que se 
caracterizam pelos seguintes valores mensais: maio $=26,1^{\circ} \mathrm{C}$ e $109 \mathrm{~mm}$; junho $=24,0^{\circ} \mathrm{C}, 25 \mathrm{~mm}$; julho $=26,0^{\circ} \mathrm{C}, 13 \mathrm{~mm}$; agosto $=25,7^{\circ} \mathrm{C}, 12 \mathrm{~mm}$.

O delineamento experimental adotado foi o de blocos casualizados, com cinco tratamentos $(0 ; 120$; $240 ; 360$ e $480 \mathrm{~kg} \mathrm{ha}^{-1}$ de $\mathrm{P}_{2} \mathrm{O}_{5}$ ) e quatro repetições. Cada unidade experimental foi composta por 4 linhas de $7 \mathrm{~m}$ de comprimento, sendo a área útil da parcela estabelecida pelas duas linhas centrais com uma bordadura de $1 \mathrm{~m}$ em cada extremidade, perfazendo uma área de $10 \mathrm{~m}^{2}$ e contendo 40 plantas.

A irrigação foi realizada por tubo gotejador com emissores espaçados em $0,30 \mathrm{~m}$, com vazão de 4 litros por hora, aplicada conforme a necessidade da cultura.

Aos 75 dias após o plantio no campo, foram avaliadas as seguintes variáveis de produção: produção total de frutos, estimada pela pesagem de todos os frutos colhidos por planta; produção comercial de frutos (frutos com massa entre 1,1 e 2,2 kg e coloração amarelo ouro), estimada pela pesagem de todos os frutos comerciais por planta, dividido pelo número de frutos; massa por fruto comercial, determinada pela pesagem de todos os frutos comerciais colhidos da planta; número de frutos por planta, determinada pela contagem de todos os frutos comerciais da planta.

As variáveis físicas analisadas foram: diâmetro, comprimento e espessura da polpa, que foram determinados pela avaliação de uma amostra composta por 12 frutos comerciais de cada parcela.

Para as variáveis químicas, foi retirada uma fatia longitudinal de cada um dos 12 frutos comerciais amostrados por parcela, os quais foram descascados e $100 \mathrm{~g}$ da parte central da fatia foi homogeneizada em liquidificador com $100 \mathrm{~cm}^{3}$ de água deionizada, passando a seguir por uma peneira com malha de $1 \mathrm{~mm}$ para a retirada do material grosseiro. $\mathrm{O}$ material que passou pela peneira foi usado para as determinações do teor de sólidos solúveis (SS), utilizando refratômetro de mesa, modelo ATAGO 3 T, obtendose os valores em graus Brix (Brix), corrigidos a 20 ${ }^{\circ} \mathrm{C}$ (COELHO et al., 2003); acidez titulável (AT), adicionando-se água destilada ao extrato da polpa até completar $50 \mathrm{~mL}$, mais duas gotas de solução de fenolftaleína a $2 \mathrm{~g} \mathrm{~L}^{-1}$, e após isso titulação com solução de $\mathrm{NaOH} 0,1 \mathrm{~N}$, padronizada com solução de biftalato de potássio $0,1 \mathrm{~N}$, sendo os resultados expressos em porcentagem de ácido cítrico (IAL, 2005). O índice de maturação foi determinado através da relação entre sólidos solúveis e acidez titulável (SS/AT). A média dos 12 frutos foi calculada para cada variável e usada como valor representativo da unidade experimental.

A análise de variância dos dados obtidos foi realizada pelo teste $\mathrm{F}$, e as médias foram submetidas à regressão polinomial, usando o programa Agrostat (BARBOSA; MALDONADO JR., 2010). $\mathrm{O}$ modelo estatístico adotado foi o correspondente à equação de maior grau, que apresentou o valor de $\mathrm{F}$ com maior valor significativo. No caso de equações quadráticas, o ponto de máximo de cada curva foi obtido derivando-se (em função das doses) a equação correspondente.

\section{RESULTADOS E DISCUSSÃO}

As médias das variáveis físicas e químicas avaliadas neste trabalho estão apresentadas na Tabela 1, acompanhadas pelos resultados da análise de variância (teste $\mathrm{F})$, coeficiente de variação $(\mathrm{CV})$, bem como teste $\mathrm{F}$ das análises de regressão polinomial. $\mathrm{O}$ coeficiente de variação de todas as variáveis medidas ficou na faixa compreendida entre $1,01 \%$ e $8,11 \%$, indicando que o experimento foi bem conduzido e avaliado, com boa coerência dos resultados.

Os dados de produção total de frutos, produção comercial de frutos, massa e número de frutos estão apresentados na Figura 1, onde pode ser observado que houve influência das doses de $\mathrm{P}_{2} \mathrm{O}_{5}$, em todas as variáveis de produção.

Os resultados de número, massa média e produção de frutos estão apresentados na Figura 2. Tanto para a produção total como para a produção comercial de frutos, a maior produtividade foi obtida com a dose 273,5 kg ha-1 $\mathrm{P}_{2} \mathrm{O}_{5}$ (Figura 2B). Comparando os valores médios de produção total e comercial de frutos obtidos nas diferentes doses, observou-se que a produção comercial foi cerca de $30 \%$ menor que a total.

Para massa de fruto comercial, o maior valor obtido foi de $2,14 \mathrm{~kg}$ com a dose $275,1 \mathrm{~kg}$ ha ${ }^{-1}$ de $\mathrm{P}_{2} \mathrm{O}_{5}$. $\mathrm{O}$ valor máximo do número de frutos comerciais por planta também foi estimado numa dose muito próxima à mencionada $\left(278,4 \mathrm{~kg} \mathrm{ha}^{-1}\right.$ de $\mathrm{P}_{2} \mathrm{O}_{5}$ ), revelando que a dose ideal para a máxima eficiência produtiva da planta encontra-se entre esses valores (Figura 2B).

Os resultados da resposta das plantas de melão em relação a doses crescentes de fósforo, dependendo da condição do cultivo, nem sempre são evidentes. Por exemplo, no trabalho de Faria et al. (1994), onde se estudou o efeito de quatro doses de $\mathrm{P}\left(0 ; 60 ; 120\right.$ e $240 \mathrm{~kg} \mathrm{ha}^{-1}$ de $\left.\mathrm{P}_{2} \mathrm{O}_{5}\right)$ na produção, foram observados aumentos da massa média de frutos, concordando com os resultados da presente pesquisa. Por outro lado, Silva et al. (2007), testando diferentes fontes e doses de P entre 0 e $150 \mathrm{~kg} \mathrm{ha}^{-1} \mathrm{de}$ $\mathrm{P}_{2} \mathrm{O}_{5}$ na produção do melão, não encontraram respos- 
tas significativas para essa variável, quando testadas num solo com $23 \mathrm{mg} \mathrm{dm}^{-3} \mathrm{P}$, o que não difere muito do solo do presente experimento $\left(18 \mathrm{mg} \mathrm{dm}^{-3} \mathrm{P}\right)$.

Conforme os dados da Figura $1 \mathrm{~b}$ pode constatar-se que a produção total e a produção comercial de frutos, massa e número de frutos foram reduzidos com doses acima de $278 \mathrm{~kg} \mathrm{ha}^{-1}$ de $\mathrm{P}_{2} \mathrm{O}_{5}$. No trabalho de Silva et al. (2010), que estudaram efeito de doses de diferentes fontes e doses de fósforo, a produtividade de frutos também apresentou uma curva semelhante à obtida no presente estudo, embora nas condições daquele trabalho os valores máximos ocorreram em doses inferiores às do presente trabalho. Esse comportamento sugere que existe um efeito negativo de doses elevadas de fósforo na produção das plantas de melão-amarelo. Não é comum observar-se interferência negativa do fósforo na produção das plantas; entretanto, segundo Marschner (2002), elevadas concentrações de fósforo podem reduzir a fotossíntese devido à exportação excessiva de triose-P da mitocondria para o citossol, o que prejudica a regeneração da RuBP e, por conseguinte, a fixação de $\mathrm{CO}_{2}$ no processo fotossintético. Além disso, Prado (2008) menciona que o fósforo também pode apresentar efeitos depressivos sobre a utilização dos micronutrientes catiônicos pelas plantas, especialmente do Zn, além de outros como $\mathrm{Cu}, \mathrm{Fe}$ e $\mathrm{Mn}$, em menor intensidade.

As doses de $\mathrm{P}_{2} \mathrm{O}_{5}$ influenciaram positivamente o diâmetro, o comprimento de frutos e a espessura de polpa de frutos (Figura 3). O valor máximo estimado para o diâmetro de frutos $(13,15$ $\mathrm{cm}$ ) foi alcançado com a dose de $396,8 \mathrm{~kg} \mathrm{ha}^{-1} \mathrm{de}$ $\mathrm{P}_{2} \mathrm{O}_{5}$. O comprimento máximo estimado para os frutos $(15,45 \mathrm{~cm})$ foi obtido com a dose de 352,4 $\mathrm{kg} \mathrm{ha}^{-1}$ de $\mathrm{P}_{2} \mathrm{O}_{5}$. Com relação à espessura da polpa do fruto comercial, a dose estimada de $354,4 \mathrm{~kg} \mathrm{ha}^{-1}$ de $\mathrm{P}_{2} \mathrm{O}_{5}$ foi a que resultaria em um valor máximo esperado de 4,7 cm de espessura da polpa (Figura 3).

Observa-se que as doses estimadas pelas equações de regressão que levariam aos maiores resultados para diâmetro e comprimento de frutos, e espessura de polpa $\left(396,8 ; 352,4 ; 354,4 \mathrm{~kg} \mathrm{ha}^{-1} \mathrm{de}\right.$ $\mathrm{P}_{2} \mathrm{O}_{5}$, respectivamente) foram superiores às doses que resultariam nos melhores resultados em produção total e comercial de frutos, massa média dos frutos e número de frutos por planta $(273,5 ; 275,1$ e 278,4 $\mathrm{kg} \mathrm{ha}^{-1}$ de $\mathrm{P}_{2} \mathrm{O}_{5}$, respectivamente). Esses resultados sugerem que doses acima das ótimas para se obter as melhores produções induziriam pequenos aumentos nas dimensões dos frutos (cerca de 1\%), mas menor massa por fruto (provavelmente frutos menos densos) e menor produção. Dessa maneira, seria necessária a aplicação de cerca de $30 \%$ a mais em fertilizante para se obter uma melhoria praticamente imperceptível pelo consumidor no que se refere ao diâmetro e comprimento de frutos e espessura de polpa. Neste caso, certamente o aumento do custo de produção e diminuição da produtividade não seria interessante para o produtor. Embora não tenha sido objetivo do presente trabalho calcular a dose econômica, é importante ressaltar que, dependendo do custo do fertilizante e do preço do produto naquele momento, a dose que induz à máxima produtividade não implica que seria a mais econômica. Pois, devese levar em conta que à medida que a produtividade vai aproximando-se do valor máximo, a curva de respostada tende a ter uma tangente cada vez menos inclinada em relação ao eixo das doses, significando que seria necessário um aumento grande da dose para se conseguir pequenos aumentos de produtividade (Figura 2B). Portanto, a dose econômica vai depender da relação custo/benefício, num determinado momento.

Para sólidos solúveis, não houve efeito das doses de P (Tabela 1, Figura 4). Os valores médios de Brix variaram de $12,52 \%$ no tratamento-testemunha a $12,73 \%$ com a maior dose testada, propiciando uma média geral de $12,66 \%$. Silva et al. (2007), estudando doses de nitrogênio e fósforo $\left(0 ; 50 ; 100\right.$ e $150 \mathrm{~kg} \mathrm{ha}^{-1}$ de $\mathrm{P}_{2} \mathrm{O}_{5}$ ) na cultura do melão, também não observaram influência do P nesta variável. Por outro lado, Silva et al. (2009), estudando diferentes fontes e doses de fósforo em melão orgânico, constataram que a dose de $320 \mathrm{~kg} \mathrm{ha}^{-1}$ proporcionou valor significativamente superior comparado com o do tratamento-testemunha. Paduan et al. (2007), avaliando qualidade de frutos de diferentes tipos de melão em ambientes protegidos, obteve valores de Brix acima de $12 \%$ para o Net Melon, semelhante aos valores encontrados neste estudo. Segundo GORGATTI NETO et al. (1994) os frutos com Brix inferior a 9\% não são comercializáveis; de 9\% a 12\% são comercializáveis, sendo que frutos com valor acima de $12 \%$ são considerados melões extras. Portanto, os valores obtidos neste estudo indicam qualidade extra para os frutos de todos os tratamentos. Os valores elevados de Brix neste trabalho são também devidos à cultivar 'Goldex' usada no experimento, que se caracteriza por comumente apresentar valores de Brix acima de $12 \%$.

No caso da acidez, em primeira instância, o teste $\mathrm{F}$ indicou efeito não significativo $(\mathrm{P}>0,05)$ das doses de fósforo testadas (Tabela 1). Entretanto, levando em conta que o comportamento das médias desta variável foi muito parecido com as das variáveis físicas e considerando também que a análise de variância da equação quadrática para acidez indicou um valor de $\mathrm{F}$ próximo do limite de significância 
( $\mathrm{F}=3,7 ; \mathrm{P}=0,0794)$, optou-se por apresentar tais dados na Figura 4 para melhor visualização e análise dos mesmos. Dentro desse contexto, poderia ser afirmado que houve um efeito, embora bastante discreto, das doses de $\mathrm{P}$ aplicadas no solo sobre a acidez titulável dos frutos (Tabela 1, Figura 4), com uma resposta quadrática semelhante à dos resultados de produção (Figuras 2), tendo seu ponto de máximo na dose estimada de $211 \mathrm{~kg} \mathrm{ha}^{-1}$ de $\mathrm{P}_{2} \mathrm{O}_{5}$ e valor de 114,52 $\mathrm{mg} / 100 \mathrm{~g}$. A comparação dos dados da acidez (Figura 4) com os das variáveis físicas (Figuras 2 e 3 ) sugere que doses muito elevadas de $\mathrm{P}$, além de prejudicar a produção total e comercial de frutos, também podem refletir-se em frutos menos ácidos.
O índice de maturação foi determinado neste trabalho, pois segundo Chitarra e Chitarra (1990), este índice é uma das melhores formas de avaliar o sabor dos frutos, dando uma boa ideia do equilíbrio entre SS e AT. Os valores do índice de maturação observado neste trabalho foram superiores a 25:1, e os de AT foram menores que $0,5 \%$ em todas as doses estudadas, valores estes que indicam boa qualidade comercial dos frutos, pois, em melão, o fruto pode ser considerado adequado para o consumo quando esta relação é superior a 25:1 e quando a acidez é igual ou menor que 0,5 \% (CRUESS, 1973). Entretanto, neste trabalho, não se verificou influência das doses de fósforo sobre o índice de maturação (SS/AT).

TABELA 1 - Principais atributos químicos da camada de 0-20 $\mathrm{cm}$ do solo da área experimental, determinados conforme indicações de Raij et al. (2001).

\begin{tabular}{|c|c|c|c|c|c|c|c|c|c|}
\hline \multirow{2}{*}{$\begin{array}{c}\mathrm{pH} \\
\left(\mathrm{CaCl}_{2}\right)\end{array}$} & \multirow{2}{*}{$\begin{array}{l}\text { Mat.Org. } \\
\left(\mathrm{mg} \mathrm{dm}^{-3}\right)\end{array}$} & \multirow{2}{*}{$\begin{array}{l}\text { P - resina } \\
\left(\mathrm{mg} \mathrm{dm}^{-3}\right)\end{array}$} & $\mathbf{K}$ & $\mathrm{Ca}$ & $\mathrm{Mg}$ & $\mathbf{H}+\mathbf{A l}$ & SB & CTC & \multirow{2}{*}{$\begin{array}{l}\mathrm{V} \\
\%\end{array}$} \\
\hline & & & \multicolumn{6}{|c|}{$\mathrm{mmol} \mathrm{dm}^{-3}$} & \\
\hline 5,5 & 11 & 18 & 1 & 20 & 7 & 15 & 28,0 & 43,0 & 65,1 \\
\hline
\end{tabular}

TABELA 2 - Médias dos tratamentos (Doses de $\mathrm{P}_{2} \mathrm{O}_{5}$ ) para massa de frutos por planta (MFP); Número médio de frutos por planta (NFP); Produtividade de frutos totais (PT); Produtividade de frutos comerciais (PC); Diâmetro dos frutos (D); Comprimento dos frutos (C); Espessura da polpa (E); sólidos solúveis (Brix) e Acidez titulável (Acidez), acompanhadas dos resultados da análise de variância dos dados pelo teste $\mathrm{F}(\mathrm{F})$ e coeficiente de variação $(\mathrm{CV} \%)$, bem como teste $\mathrm{F}$ da análise de regressão polinomial para o modelo linear $(\mathrm{F}-\mathrm{L})$, quadrático $(\mathrm{F}-\mathrm{Q})$, cúbico $(\mathrm{F}-\mathrm{C})$ e desvio (F-DV). ${ }^{* *}=$ significativo $\operatorname{com} \mathrm{P}<0,01$; $*$ = significativo $\operatorname{com} \mathrm{P}<0,05$; ${ }^{\text {ns }}=$ não significativo $(\mathrm{P}>0,05)$.

\begin{tabular}{cccccccccc}
\hline $\begin{array}{c}\text { Doses } \\
\mathbf{P}_{2} \mathbf{O}_{5} \\
\left(\mathrm{~kg} \mathrm{ha}^{-1}\right)\end{array}$ & $\begin{array}{c}\text { MFP } \\
(\mathrm{kg})\end{array}$ & NFP & $\begin{array}{c}\mathbf{P T} \\
\left(\mathrm{t} \mathrm{ha}^{-1)}\right.\end{array}$ & $\begin{array}{c}\mathbf{P C} \\
\left(\mathrm{t} \mathrm{ha}^{-1)}\right.\end{array}$ & $\begin{array}{c}\mathbf{D} \\
(\mathrm{cm})\end{array}$ & $\begin{array}{c}\mathbf{C} \\
(\mathrm{cm})\end{array}$ & $\begin{array}{c}\mathbf{E} \\
(\mathrm{mm})\end{array}$ & $\begin{array}{c}\text { Brix } \\
(\%)\end{array}$ & $\begin{array}{c}\text { Acidez } \\
(\mathrm{g} / 100 \mathrm{~g})\end{array}$ \\
\hline 0 & 1,46 & 1,24 & 38,28 & 29,19 & 12,56 & 14,07 & 43,0 & 12,69 & 108,64 \\
120 & 2,06 & 1,61 & 54,57 & 41,14 & 12,66 & 14,89 & 45,9 & 12,77 & 110,04 \\
240 & 2,20 & 1,65 & 60,04 & 44,04 & 13,08 & 15,48 & 4,69 & 12,69 & 117,32 \\
360 & 1,87 & 1,52 & 51,39 & 37,43 & 13,26 & 15,22 & 4,65 & 12,52 & 109,44 \\
480 & 1,89 & 1,50 & 49,79 & 37,64 & 13,06 & 15,37 & 4,68 & 12,63 & 102,63 \\
\hline $\mathrm{F}$ & $48,8^{* *}$ & $23,4^{* *}$ & $53,6^{* *}$ & $43,0^{* *}$ & $8,6^{* *}$ & $6,3^{*}$ & $9,4^{*}$ & $0,8^{\mathrm{ns}}$ & $1,4^{\mathrm{ns}}$ \\
$\mathrm{CV}(\%)$ & 4,22 & 4,43 & 4,32 & 4,48 & 1,57 & 3,00 & 2,35 & 1,64 & 8,11 \\
\hline $\mathrm{F}-\mathrm{L}$ & $38,1^{* *}$ & $21,2^{* *}$ & $32,7^{* *}$ & $24,1^{* *}$ & $25,8^{* *}$ & $18,5^{* *}$ & $26,9^{* *}$ & $1,2^{\mathrm{ns}}$ & $0,5^{\mathrm{ns}}$ \\
$\mathrm{F}-\mathrm{Q}$ & $110,7^{* *}$ & $55,2^{* *}$ & $147,9^{* *}$ & $107,6^{* *}$ & $3,8^{\mathrm{ns}}$ & $5,5^{*}$ & $7,9^{*}$ & $0,1^{\mathrm{ns}}$ & $3,7^{\mathrm{ns}, \#}$ \\
$\mathrm{~F}-\mathrm{C}$ & $33,4^{* *}$ & $15,9^{* *}$ & $26,51^{* *}$ & $34,8^{* *}$ & $4,7^{\mathrm{ns}}$ & $0,5^{\mathrm{ns}}$ & $2,4^{\mathrm{ns}}$ & $1,4^{\mathrm{ns}}$ & $0,3^{\mathrm{ns}}$ \\
F-DV & $13,19^{* *}$ & $1,4^{\mathrm{ns}}$ & $7,11^{*}$ & $5,6^{*}$ & $0,1^{\mathrm{ns}}$ & $0,8^{\mathrm{ns}}$ & $0,2^{\mathrm{ns}}$ & $0,5^{\mathrm{ns}}$ & $1,0^{\mathrm{ns}}$ \\
\hline
\end{tabular}

\# valor de $\mathrm{F}$ significativo em $\mathrm{P}=0,07$. 


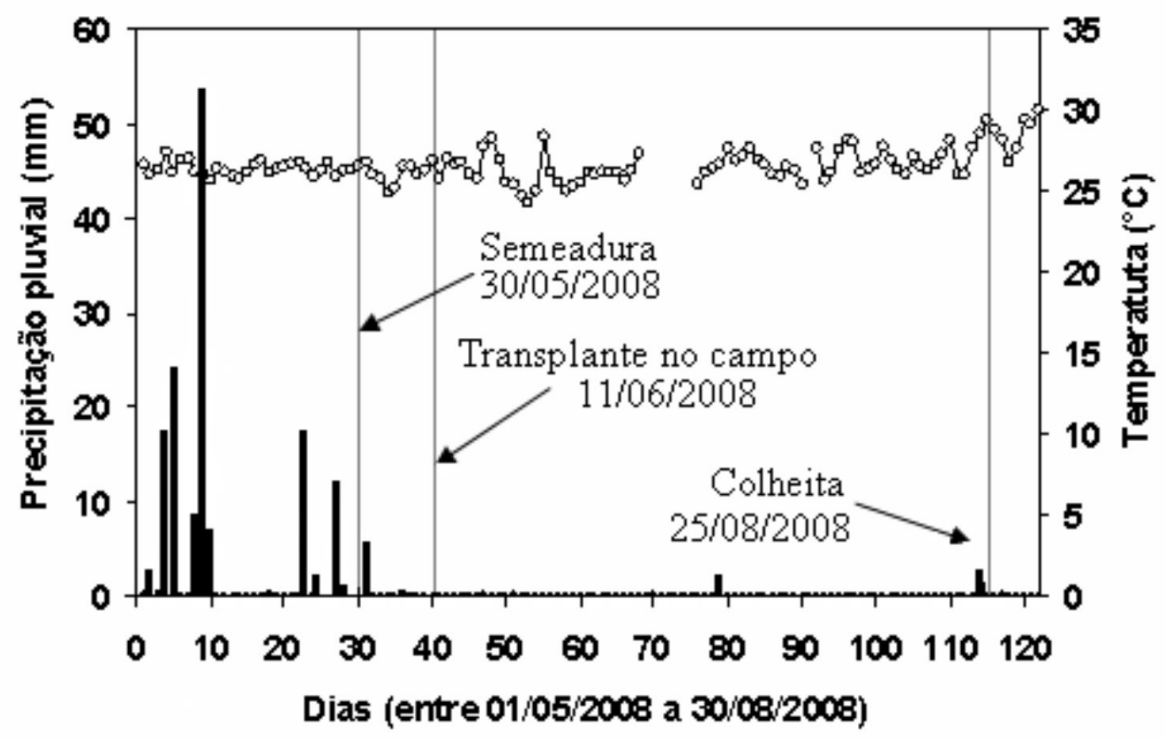

FIGURA 1 - Precipitação pluvial diária $(\bullet)$ e temperatura média diária $(\circ)$ durante o período do experimento.

A

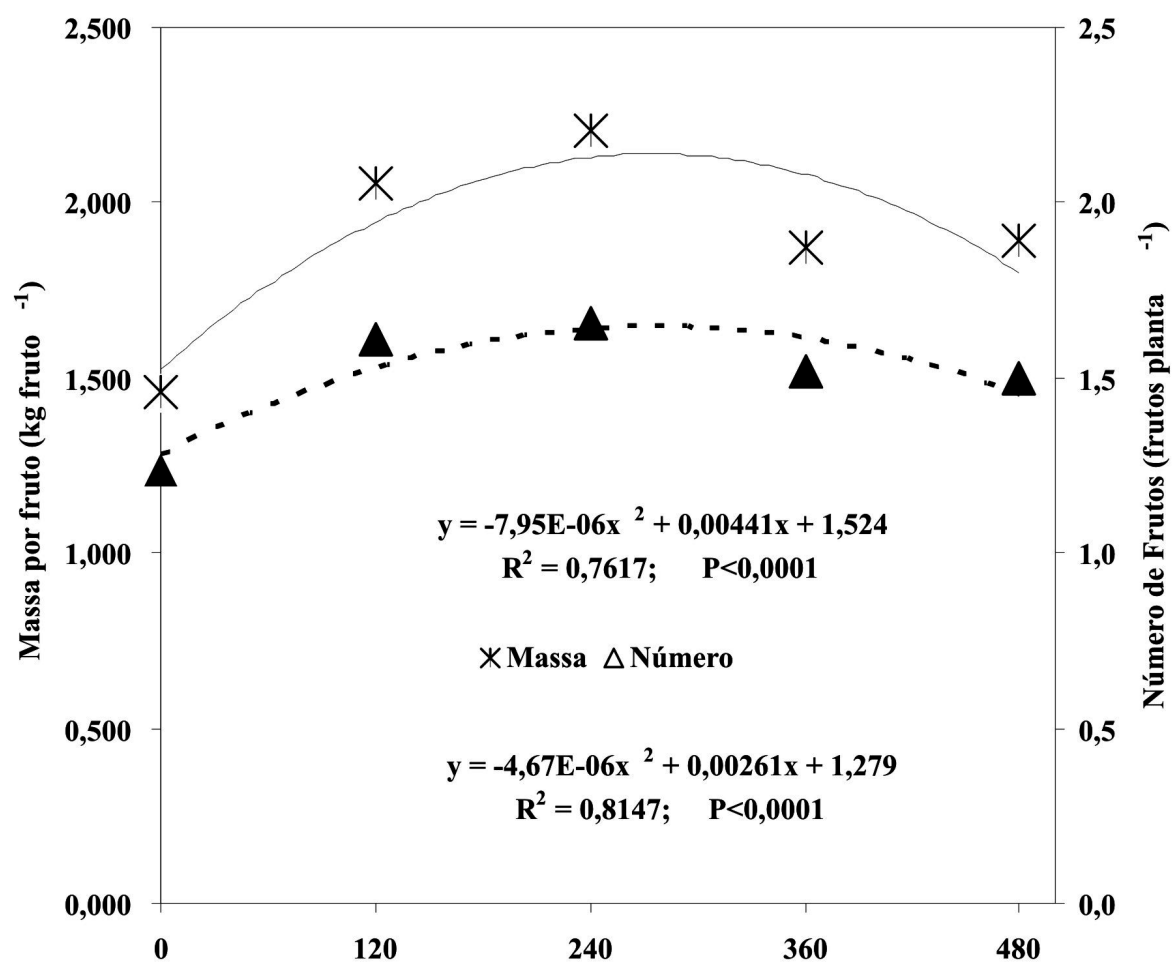

continua... 
continuação.

$\mathrm{B}$

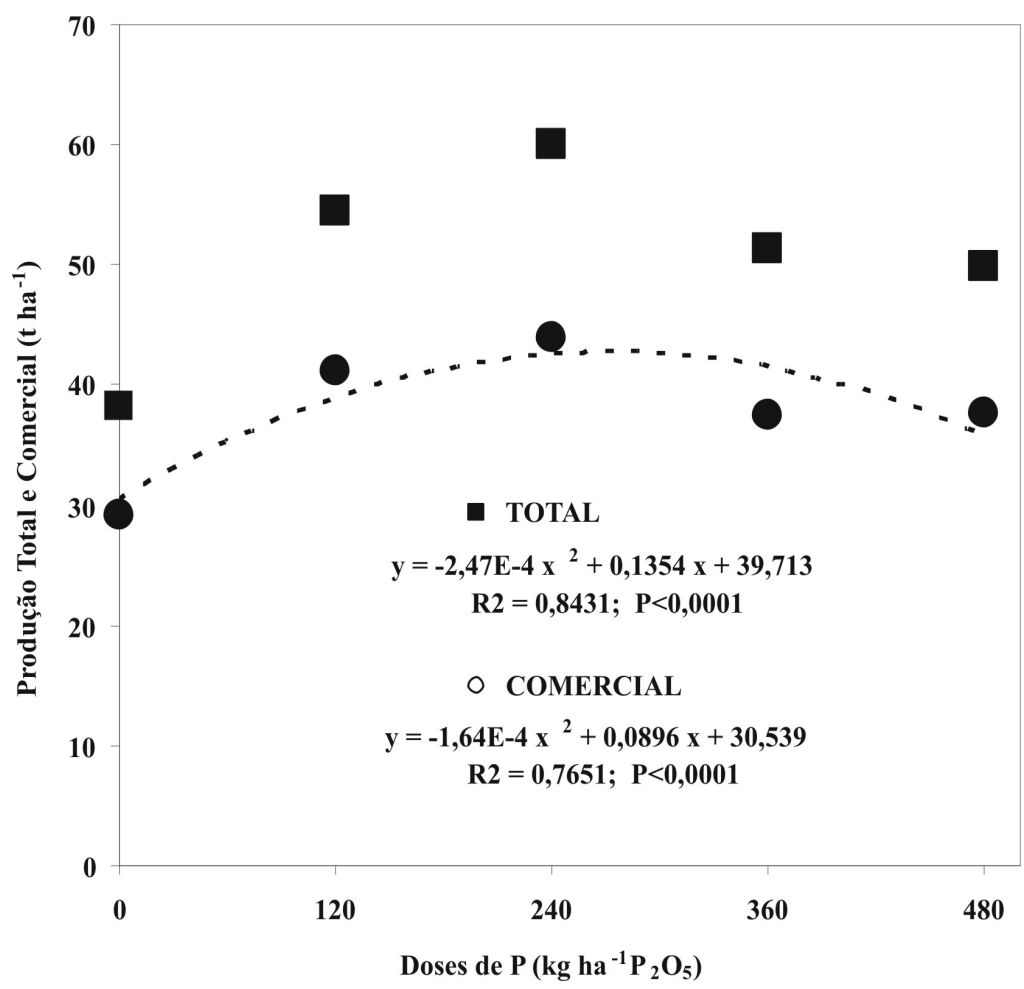

FIGURA 2 -Efeito de doses de P sobre a massa e o número de frutos comerciais por planta (A) e os reflexos na Produtividade Total e Comercial de frutos (B).

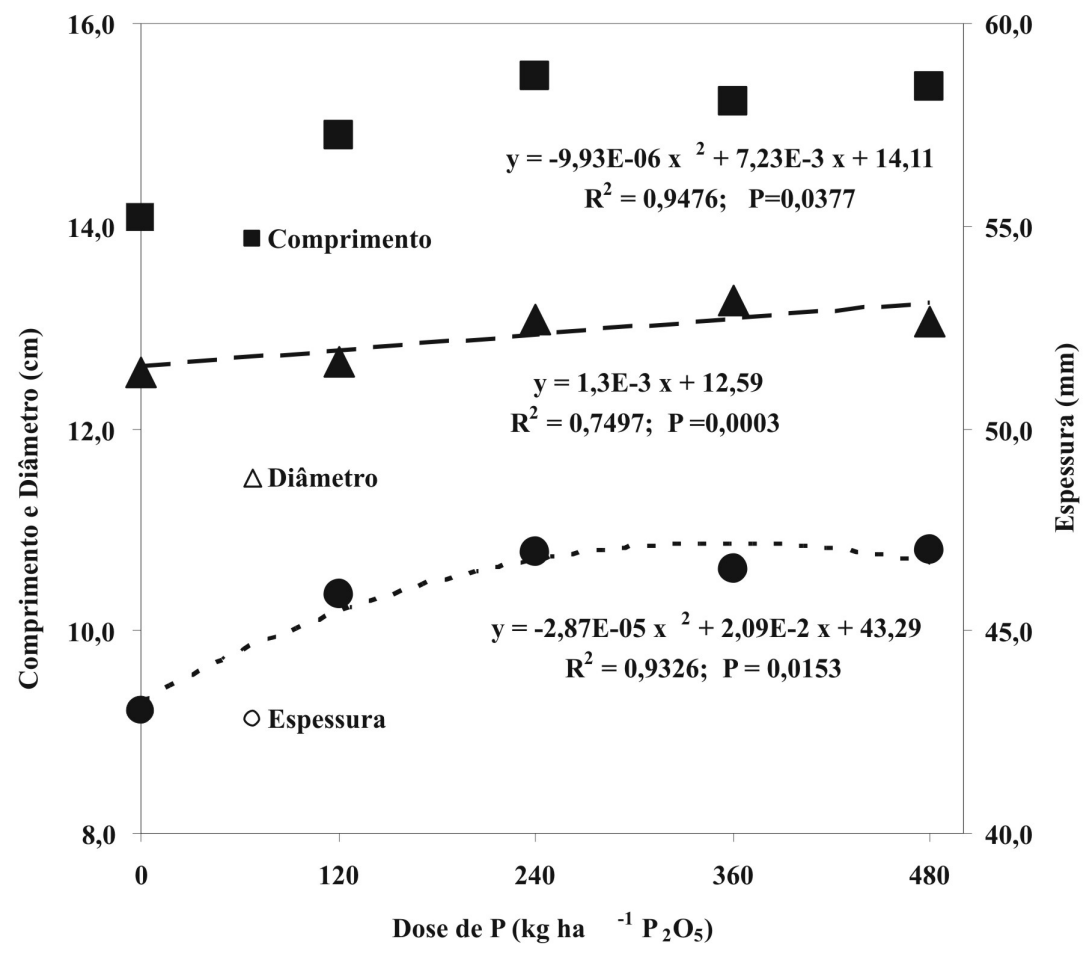

FIGURA 3 - Efeito de doses de P sobre o comprimento, diâmetro e espessura de polpa de frutos comerciais. 


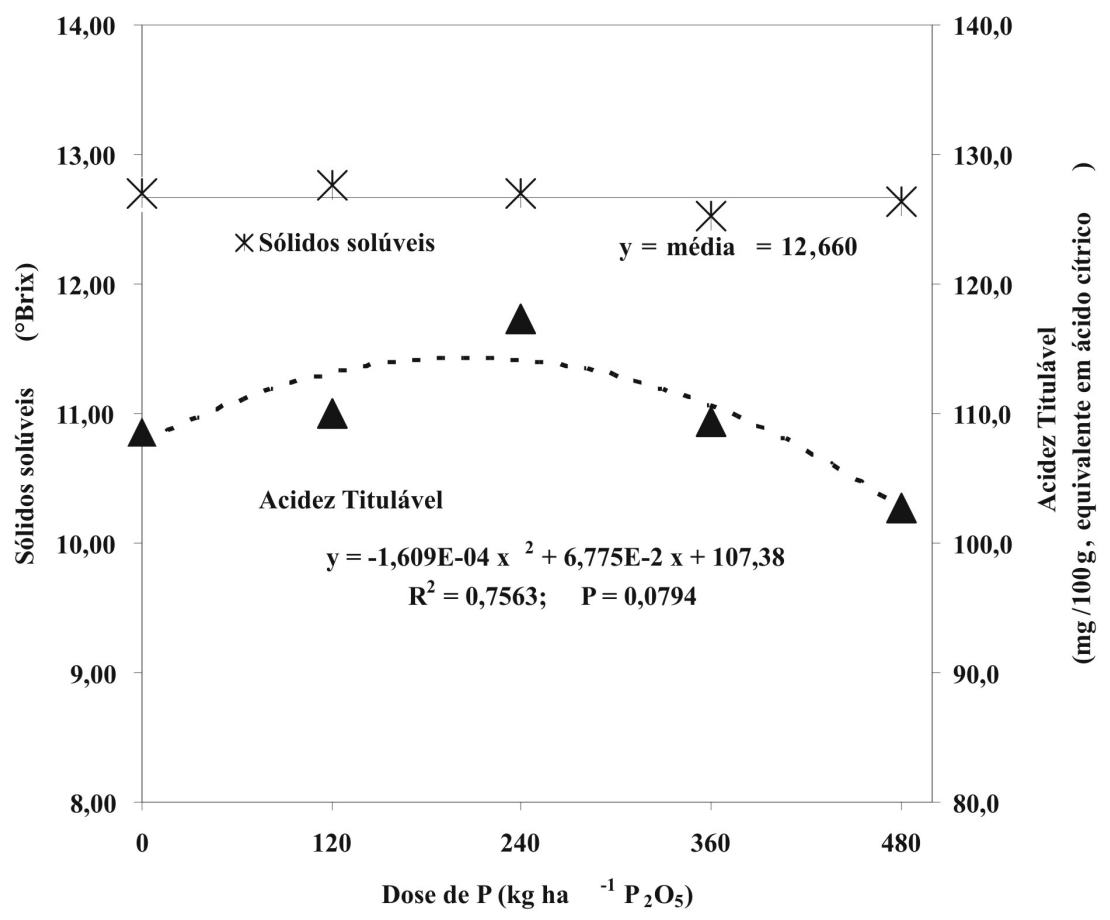

FIGURA 4 - Efeito de doses de P sobre: (a) teor de sólidos solúveis (\%); (b) acidez titulável (mg de ácido Cítrico por $100 \mathrm{~g}$ de polpa).

\section{CONCLUSÕES}

1-A produção total e comercial, assim como massa média e número de frutos por planta aumentam com as doses de fósforo aplicadas, atingindo valores máximos entre 275 e $278 \mathrm{~kg} \mathrm{ha}^{-1}$ de $\mathrm{P}_{2} \mathrm{O}_{5}$.

2 - Doses acima de $278 \mathrm{~kg} \mathrm{ha}^{-1}$ de $\mathrm{P}_{2} \mathrm{O}_{5}$ reduzem a produtividade de frutos classificados como comerciais.

3 - O comprimento, o diâmetro e a espessura da polpa dos frutos aumentam até atingir um máximo na dose de $355 \mathrm{~kg} \mathrm{ha}^{-1}$ de $\mathrm{P}_{2} \mathrm{O}_{5}$, com aumento pouco expressivo em doses acima da que proporciona máxima produtividade.

4- O teor de sólidos solúveis totais (Brix), a acidez titulável e a ralação Brix/Acidez titulável não são alterados de forma significativa $(\mathrm{P}>0,05)$ pela variação da dose de fósforo aplicada.

5 - Para as condições de fertilidade do solo, onde foi conduzida a cultura do melão, recomenda-se uma dose ao redor de $275 \mathrm{~kg} \mathrm{ha}^{-1}$ de $\mathrm{P}_{2} \mathrm{O}_{5}$.

\section{REFERÊNCIAS}

AGRIANUAL: anuário da agricultura brasileira. São Paulo: FNP Consultoria e AgroInformativos, 2009. 496p.

BARBOSA, J. C.; MALDONADO JÚNIOR, W. Sistemas para análises estatísticas de ensaios agronômicos. Jaboticabal: FCAV-UNESP, 2010.

BRITO, L. T. L.; SOARES, J. M. ; FARIA, C. M. B. ; COSTA, N. D. Fontes de fósforo aplicadas na cultura do melão via água de irrigação. Revista Brasileira de Engenharia Agrícola e Ambiental, Campina Grande, v.4, n.1, p.19-22, 2000.

COELHO, E. L.; FONTES, P. C. R.; FINGER, F. L.; CARDOSO, A. A. Qualidade do fruto de melão rendilhado em função de doses de nitrogênio. Bragantia,Campinas,v.62, n.2, p.173-178, 2003.

CHITARRA, M.F.I.; CHITARRA, A.B. Pós-colheita de frutos e hortaliças: fisiologia e manejo. Lavras: Escola Superior de Agricultura de Lavras /FAEP, 1990. 320p. 
CRUESS, W.V. Produtos industriais de frutos e hortaliças. São Paulo: Edgard Blücher, 1973. 446 p.

FARIA, C.M.B.; PEREIRA, J.R.; POSSIDIO, E.L. de. Adubação orgânica e mineral na cultura do melão num vertissolo do Submédio São Francisco. Pesquisa Agropecuária Brasileira, Brasília, v.8, n.2, p.1191-1197, 1994.

GORGATTI NETO, A.; GAYET, J. P.; BEINROTN, E. W.; MATALLO, M.; GARCIA, E. E. C.; GARCIA, A. E.; ARDITO, G. F. G.; BORDIN, M. R. Melão para exportação: procedimento de colheita e póscolheita. Brasília: Embrapa-SPI, 1994. 37p. (Série Publicações Técnicas Frupex, 6).

GRANGEIRO, L.C.; CECÍLIO FILHO, A.B.; BRAZ, L.T.; GONÇALVES, F.C. Cultivo de melãoamarelo. Jaboticabal: Unesp, 2002. 30p.

IAL - Instituto Adolfo Lutz. Métodos físico-químicos para análise de alimentos. 4.ed. Brasília: IAL, 2005. 1018p.

MARSCHENER, H. Mineral nutrition of higher plants. San Diego: Academic Press, 2002. 889p.

MEDEIROS, R. M. Climatologia no município de Teresina. Teresina: Secretaria do Meio Ambiente e Recursos Naturais do Estado do Piauí, 2006. 28p.

NOVAIS, R. F.; JOT SMYTH, T.; NUNES, F. N. Fósforo. In: NOVAIS, R. F.; ALVAREZ V, V. H.; BARROS, N. F.; FONTES, R. L. F.; CANTARUTTI, R.B.; NEVES, J. C. L. Fertilidade do solo. Viçosa: Sociedade Brasileira de Ciências do Solo, 2007.p.471-548

PADUAN, M. T.; RAQUEL PIRES CAMPOS, R. P.; CLEMENTE, E. Qualidade dos frutos de tipos de melão, produzidos em ambiente protegido. Revista Brasileira de Fruticultura, Jaboticabal, v. 29, n. 3, p. 535-539, 2007.

PINTO, J.M.; SOARES, J.M.; PEREIRA, J.R.; COSTA, N.D.; BRITO, L.T. de L.; FARIA, C.M.B.;
MACIEL, J.L. Sistema de cultivo de melão com aplicação de fertilizantes via água de irrigação. Petrolina: Embrapa-CPATSA/Petrobrás, 1996. 24p. (Circular Técnica, 36). (não consta no texto)

PRADO, R. M. Nutrição de plantas. São Paulo: Editora. UNESP, 2008. 407p

RAIJ B.V.; ANDRADE, J.C.; CANTARELLA, H.; QUAGGIO, J.A. Análise química para avaliação da fertilidade dos solos tropicais. Campinas: Instituto Agronômico, 2001. 285p

SANTOS, H. G. dos. Sistema brasileiro de classificação de solos. 2.ed. Rio de Janeiro: Embrapa Solos, 2006. 306p.

SILVA, D. J.; FARIA, C. M. B.; PINTO, J. M.; COSTA, N. D.; GAVA, C. A. T.; DIAS, R. C. S.; GOMES , T. C. A.; ARAÚJO, J. L. P. Cultivo de melão orgânico: fosfatos naturais como fontes alternativas de fósforo. Revista Brasileira de Fruticultura, Jaboticabal,v. 31, n. 2, p. 559-566, 2009.

SILVA, F. N.; MAIA, S. S. S.; AQUINO, B. F.; HERNANDEZ, F. F. F. Rendimento de melão-amarelo em resposta à aplicação de diferentes fontes e doses de fósforo. Revista Verde, Cataguases, v.5, n.2, p. 213-221, 2010.

SILVA, P. S. L.; RODRIGUES, V. L. P.; AQUINO, B. F.;MEDEIROS, J. F.; SILVA, J. Resposta do meloeiro à aplicação de doses de nitrogênio e fósforo. Caatinga, Mossoró,v.20, n.1, p.64-70, 2007.

VIANA, T. V. A.; SALES, I. G. M.; SOUSA, V. F.; AZEVEDO, B. M.; FURLAN, R. A.; COSTA, S. C. Produtividade do meloeiro fertirrigado com potássio em ambiente protegido. Horticultura Brasileira, Brasilia, v. 25, n. 3, 2007.

WANG, X.; SHEN, J.; LIAO, H. Acquisition or utilization, which is more critical for enhancing phosphorus efficiency in modern crops? Plant science, Limerick,v. 179, p. 302-306, 2010. 